\title{
Effects of Increasing Slaughter Weight on Production Efficiency and Carcass Quality of Finishing Gilts and Barrows
}

\author{
Jin Yeun Jeong ${ }^{1}$, Byung Chul Park², Duck Min Ha, Man Jong Park¹, Seon Tea Joo${ }^{1}$, and Chul Young Lee* \\ Regional Animal Industry Center, Jinju National University, Jinju 660-758, Korea \\ ${ }^{1}$ Division of Applied Life Science, Gyeongsang National University, Jinju 660-701, Korea \\ ${ }^{2}$ CJ Feed Research Institute, Incheon 400-03, Korea
}

\begin{abstract}
A total of 582 gilts and barrows were analyzed to investigate the regressive relationships to slaughter weight (SW) of variables related to production efficiency and pork quality. Average initial weights and SW were 88.6 and $122.5 \mathrm{~kg}$, respectively, for gilts and 88.7 and $121.4 \mathrm{~kg}$, respectively, for barrows. Average daily gain and gain:feed ratio were not affected by SW. Backfat thickness, which was significantly greater $(p<0.01)$ in barrows $(23.3 \mathrm{~mm})$ than in gilts $(20.7 \mathrm{~mm})$, increased with increasing SW $(0.21 \mathrm{~mm} / \mathrm{kg} ; p<0.001)$. When the 4-notch carcass yield and quality grades were quantified according to an arbitrary 1 point-per-1 notch scale, the former, but not the latter, regressed on $\mathrm{SW}(-0.64 / 10 \mathrm{~kg} ; p<0.01)$. The percent yield of the belly per total lean (overall mean $=20.7 \%)$ increased with increasing SW $(0.37 \% / 10 \mathrm{~kg} ; p<0.001)$, whereas in other cuts, the SW effect was negligible. The redness of the loin also increased with increasing SW $(p<0.05)$, but other physicochemical characteristics were minimally influenced by SW. In sensory evaluation, effects of SW for fresh and cooked loin, ham, and belly were mostly considered insignificant in terms of quality, albeit statistically significant in several cases. However, positive regressions on SW $(p<0.01)$ of the marbling and acceptability scores of fresh loin as well as the fat:lean ratio of fresh belly were noteworthy. Collectively, SW of approximately $125 \mathrm{~kg}$ was maximal for both sexes under the current carcass yield grading, in which $94 \mathrm{~kg}$ is the upper weight limit for grade A carcass. However, if the carcass weight limit of the grading was to be removed or broadened, the SW for gilts (but not that for barrows because of their excessive fat content at above $125-\mathrm{kg} \mathrm{SW}$ ) could be increased to $135 \mathrm{~kg}$ or greater without compromising carcass quality.
\end{abstract}

Key words: finishing pig, slaughter weight, growth, carcass, meat quality

\section{Introduction}

The slaughter weight of finishing pigs is an important variable influencing the quality of pork as well as the profitability of swine production (Kim et al., 2005). It is determined by a number of intrinsic and extrinsic factors including the genetic background of the swine, nutrition and feeding programs, and the quantitative and qualitative standards for the carcass and primal cuts demanded by the packers and consumers (Kim et al., 2005; Lee et al., 2006). With an increase of the slaughter weight of finishing pigs, fat deposition also increases eventually resulting in overfattening accompanied by decreased feed efficiency and poor carcass quality (Quijandria and Rob-

\footnotetext{
*Corresponding author: Chul Young Lee, Regional Animal Industry Center, Jinju National University, Jinju 660-758, Korea. Tel: 82-55-751-3285, Fax: 82-55-753-4422, E-mail: cylee@jinju.ac.kr
}

insion, 1971; Gu et al., 1992; Ellis et al., 1996), for which reason most pigs are slaughtered within a range of 100 to $130 \mathrm{~kg}$ worldwide (Kim et al., 2005; NASS, 2008). Domestically, the average slaughter weight is 110 to 115 $\mathrm{kg}$, which is thought to be lower than is desirable for the following reasons. Firstly, the slaughter weight in Korea is 5 to $15 \mathrm{~kg}$ lower than those in the Western countries from which most core breeding herd used in the former are imported. Furthermore, the animals used for pork production, which are mostly descendents of the imported lean-genotype core herd, have a superior ability to gain the lean at higher body weights. Secondly, domestic meat consumers, unlike Westerners, are generous to animal fat and sometimes even prefer the fat-rich cut represented by the belly.

The present group has reported the efficiency of the production of 'larger' finishing gilts and barrows weighing $125 \mathrm{~kg}$ or greater vs the $110-\mathrm{kg}$ 'average' pigs and the physicochemical and sensory quality traits of their car- 
casses and major primal cuts (Lee et al., 2006, 2007; Park et al., 2007, 2009a,b). The initial body weight in these studies was 80 or $90 \mathrm{~kg}$, whereas the target or slaughter weights were 125 or 130 for larger barrows and 130, 135, or $138 \mathrm{~kg}$ for larger gilts depending on the study. A 'medium' energy-dense diet containing 3.2 Mcal DE/kg was used in all the previous studies except the one by Park et al. (2009a); however, in a few studies where the effect of dietary energy density was investigated, a 'control' diet containing 3.4 Mcal DE/kg (Lee et al., 2007) conforming to the NRC (1998) recommendation as well as a 'low' energy-dense diet containing 3.06 (Park et al., 2009a) or 3.0 Mcal DE/kg (Park et al., 2009b) was also used. It is thus conceivable that these varying experimental conditions may have brought about considerable variation in some of the results. Further, investigation on some possible correlations between the slaughter weight and its related variables was precluded, partly because the slaughter weight was considered only as a fixed error, i.e. $110-\mathrm{kg}$ 'low' vs $125 \mathrm{-kg}$ 'high', rather than as a continuous variable in the statistical model, partly because the number of replicates in each study was not enough for the analysis. In the meantime, the numbers of animals which received the same medium-energy diet in the four previous studies (Lee et al., 2006, 2007; Park et al., 2007, 2009b) have added up to such a total as to be enough to warrant the aforementioned regression analysis. The present study was therefore undertaken to analyze the regressive relationships of production efficiency, carcass grades, and physicochemical and sensory characteristics of finishing gilts and barrows to their slaughter weights using the data from these studies.

\section{Materials and Methods}

\section{Growth performance}

Out of a total of 768 gilts and barrows born to Yorkshire $\times$ Landrace dams and Duroc sires that were used in four previous studies (Lee et al., 2006, 2007; Park et al., 2007, 2009b), 592 animals which received a same finisher diet containing 3.2 Mcal DE $/ \mathrm{kg}$ in a total of 80 pens subserved the present study (data analysis). The initial weight of the animals was either $80 \mathrm{~kg}$ (Park et al., 2009b) or $90 \mathrm{~kg}$ (the other three studies). The target slaughter weights (SW) were $110 \mathrm{~kg}$ for all the 'control' group gilts and barrows, whereas in the 'high'-SW groups, they were 125,130 , or $138 \mathrm{~kg}$ for barrows and 125,130,135, or 138 $\mathrm{kg}$ for gilts depending on the study.

\section{Slaughtering and fabrication of the carcass}

All animals were slaughtered at the abattoir of Pusan and Kyungnam Cooperative Swine Farms Association, followed by the grading and fabrication of resulting carcasses according to the standards of the Ministry of Agriculture and Forestry (MAF, 2005, 2007). For the present analyses on the yields of seven primal cuts as well as physicochemical and sensory characteristics of major primals described in the following sections, data obtained from 181 carcasses were used.

\section{Physicochemical analysis of the loin}

Muscle and fat color was determined by the CIE (1978) $\mathrm{L}^{*}$ (lightness), $\mathrm{a}^{*}$ (redness), and $\mathrm{b}^{*}$ (yellowness) standards using a chromometer (model CR-300, Minolta Camera Co., Japan); the 24-h pH was measured after homogenization of the primal sample with 10 volumes of distilled water as previously described (Lee et al., 2002). Drip loss was determined by measuring the weight loss during suspension of the muscle within an inflated plastic bag for $24 \mathrm{~h}$ at $2^{\circ} \mathrm{C}$ basically as described by Honikel (1987). Cooking loss was determined by measuring the weight loss of a muscle sample during 20-min cooking at $70^{\circ} \mathrm{C}$ of internal temperature in a water bath as described by Yang et al. (2006). Chemical composition including the contents of moisture, crude protein, and crude fat was determined following the procedure of AOAC (1990). Fatty acid composition was determined by gas chromatography following extraction of total lipid using chloroform (Folch et al., 1957) as described (Lee et al., 2002; Zanardi et al., 2000).

\section{Sensory evaluation of fresh and cooked cuts}

Sensory quality traits of fresh belly, ham, and loin, including color, aroma, off-flavor, drip, marbling, and acceptability, as well as the fat:lean ratio and balance of the belly, were evaluated by seven to twelve trained panelists according to a 9-point hedonic scale as described by Moon et al. (2006) and Yang et al. (2006). Cooked belly, ham, and loin, which had been prepared by heating $5 \times 5 \times 3 \mathrm{~cm}$ pieces of the cuts to $72^{\circ} \mathrm{C}$ in a water bath, were evaluated with respect to their color, aroma, off-flavor, juiciness, tenderness, and acceptability.

\section{Statistical analysis}

The pen was regarded as the experimental unit for the variables pertaining to growth performance, whereas in the remainder of the variables, the individual animal was used as the experimental unit. Data were analyzed as a 4 
(study) $\times 2$ (sex) completely randomized factorial design, with the previous study (Lee et al., 2006, 2007; Park et al., 2007, 2009b) and slaughter weight considered as a fixed error and a covariable, respectively, using the General Linear Model of SAS (1996). The regression procedure was used to calculate the linear responses of each variable to slaughter weight.

\section{Results and Discussion}

\section{Growth performance}

Results for growth performance of a total of 80 pens consisting of 582 gilts and barrows which subserved the present analysis/study are shown in Table 1. Least squares means for the initial weights and slaughter weights (SW; used as a synonym of final weight in this study) were approximately 89 and $122 \mathrm{~kg}$, respectively, in both sexes. Means for the individual studies are not shown in either Table 1 or the following tables not only because means for the treatment factor (study) were beyond the interest of the present analysis, but because they are potentially more misleading than informative. Average daily gain (ADG) was greater in barrows than in gilts $(p<0.01)$, but it had no relation to SW. The comparative weight gain for the two sexes of the present study is consistent with most results published in related literature (Cisneros et al., 1996; Latorre et al., 2004; Leach et al., 1996; Piao et al., 2004). As for the effect of SW, however, conflicting results have been reported. Neely et al. (1979) and Cisneros et al. (1996) have reported that ADG was not influenced by SW within a range between 110 and $127 \mathrm{~kg}$ following a 42- to $59-\mathrm{kg}$ weight gain and between 100 and $160 \mathrm{~kg}$ following a 50- to $100-\mathrm{kg}$ weight gain, respectively. In contrast, Kanis et al. (1990) have reported that ADG during 60- and 140-kg body weights was less than that during 60 and $110 \mathrm{~kg}$; in the study of Latorre et al. (2004), ADG decreased with increasing SW between 116 and $133 \mathrm{~kg}$ following a $41-$ to $58-\mathrm{kg}$ weight gain.
Conceivably, this difference between the two groups of researchers seems to reflect the difference in the genetic lean-gain potentials of the animals used in the different studies.

Average daily feed intake (ADFI), like ADG, was slightly greater in barrows than in gilts $(p<0.05)$, which is quite consistent with the results reported in related literature (Cisneros et al., 1996; Latorre et al., 2004; Piao et al., 2004). The ADFI increased slightly with increasing SW at a rate of $0.08 \mathrm{~kg} / 10-\mathrm{kg}$ SW. Piao et al. (2004) also have reported a similar result as for the effect of SW on this variable, whereas Cisneros et al. (1996) and Latorre et al. (2004) have reported no effect. These apparently conflicting results, however, should converge on a general conclusion that the feed intake of finishing pigs increases to some extent with increasing SW, the effect of which may or may not reach a statistical significance. The gain:feed or feed efficiency neither differed between the two sexes nor changed with the increase of SW. The feed efficiency has been reported either to be greater in gilts vs barrows (Latorre et al., 2004; Leach et al., 1996) or not to be influenced by the gender (Piao et al., 2004). Similarly, as for the effect of SW, either a negative effect (Latorre et al., 2004; Leach et al., 1996; Piao et al., 2004) or no effect up to $160 \mathrm{~kg}$ (Cisneros et al., 1996) has been reported. With respect to the present result, the unchanging feed efficiency up to the high SW is most likely to have resulted from a superior lean-gain ability of the animals used for the feeding trial, as has been suggested by Cisneros et al. (1996).

Backfat thickness (BFT) was greater in barrows vs gilts $(p<0.01)$ and increased linearly with increasing SW $(0.21$ $\mathrm{mm} / \mathrm{kg} ; p<0.01)$. These results on the effects of sex and SW are consistent with previous reports (Gu et al., 1992; Leach et al., 1996; Piao et al., 2004). Moreover, the slope of the regression on SW fell on the mid-point between 0.18 and $0.24 \mathrm{~mm} / \mathrm{kg}$ reported by Cisneros et al. (1996) and Latorre et al. (2004), respectively. This means that

Table 1. Growth performance of finishing gilts and barrows: effect of gender and regression on slaughter weight (SW)

\begin{tabular}{|c|c|c|c|c|c|c|}
\hline \multirow{2}{*}{ Variable } & \multicolumn{3}{|c|}{ Sex } & \multicolumn{3}{|c|}{ Regression on SW } \\
\hline & Giltt) & Barrow $^{1)}$ & $P$-value & Slope & SE & $P$-value \\
\hline Initial wt (kg) & $88.6 \pm 0.8$ & $88.7 \pm 0.8$ & 0.349 & - & - & - \\
\hline Final wt (kg) & $122.5 \pm 1.65$ & $121.4 \pm 1.6$ & 0.562 & - & - & - \\
\hline ADG (kg) & $0.82 \pm 0.01$ & $0.86 \pm 0.01$ & 0.005 & 0.001 & 0.001 & 0.089 \\
\hline ADFI (kg) & $3.20 \pm 0.04$ & $3.32 \pm 0.04$ & 0.042 & 0.008 & 0.003 & 0.002 \\
\hline Gain:feed & $0.25 \pm 0.005$ & $0.25 \pm 0.005$ & 0.847 & $<0.001$ & $<0.001$ & 0.693 \\
\hline Backfat thickness (mm) & $20.7 \pm 0.3$ & $23.3 \pm 0.3$ & $<0.001$ & 0.212 & 0.017 & $<0.001$ \\
\hline
\end{tabular}

${ }^{1)} \mathrm{LS}$ means \pm SE of 40 replicates (pens). 
based on the present results on average SW and BFT, i.e. $122.5 \mathrm{~kg}$ and $20.7 \mathrm{~mm}$ for gilts and $121.4 \mathrm{~kg}$ and 23.3 $\mathrm{mm}$ for barrows, the maximum SW would be $145 \mathrm{~kg}$ and $129.2 \mathrm{~kg}$ in the former and latter, respectively, if customers were to allow BFT only up to $25 \mathrm{~mm}$. Although this is only a hypothetical assessment, it is practically possible that BFT be a factor limiting the maximum SW for barrows.

\section{Carcass yields and grades}

Carcass weight increased at a rate of $0.78 \mathrm{~kg} / \mathrm{kg} \mathrm{SW}$ (Table 2). Dressing percentage did not differ between the two sexes. This variable increased with increasing $\mathrm{SW}$ at a rate of $0.31 \% / 10 \mathrm{~kg}$, which was close to the slope $(0.32 \% / 10 \mathrm{~kg})$ reported by Cisneros et al. (1996). Leach et al. (1996), however, have reported no effect of SW on this variable. Evidently, dressing percentage appears to change minimally with increasing SW.

The carcass yield grade, which was quantitated according to an arbitrary 1 point-per-1 notch scale, was greater in the barrow vs gilt and also regressed on SW with a slope of $-0.64 / 10 \mathrm{~kg}$. These results were almost entirely attributable to the lower carcass weight in the barrow vs gilt and an approximately one-notch drop of the grade between 125- and 130-kg SW because of the strictly observed range of carcass weight allowed for the higher grades. More specifically, the ratio of the A- and B-grade carcasses was $80 \%$ to $85 \%$ between 110 - and $125-\mathrm{kg} \mathrm{SW}$, but by $130 \mathrm{~kg}$, it declined to $<25 \%$ meaning a $>75 \%$ ratio of grades $\mathrm{C}$ and $\mathrm{D}$. The negative effect of $\geq 125-\mathrm{kg} \mathrm{SW}$ on the yield grade diminished slightly in the last trial (Park et al., 2009b) vs the first three (Lee et al., 2006, 2007; Park et al., 2007) because of a recent $1-\mathrm{kg}$ upward adjustment in the upper limit of the carcass weight required for higher grades (MAF, 2007); however, this did not influence the overall relationship at all between SW and the yield grade.
The carcass quality grade, which has been a]pplied to the pig carcass from late 2007 (MAF, 2007), had nothing to do with SW when its four notches were numerated as in the yield grade. Consequently, the per-kg carcass price was determined almost entirely by the yield grade even under the new carcass grading standard (Park et al., 2009b), which was virtually identical to the results of the previous studies performed at the time the pig carcass was evaluated only according to the yield grade (Lee et al., 2006, 2007; Park et al. 2007; Piao et al., 2004). In other words, the quality grade is currently being overshadowed by the yield grade, even though the former has been adopted with the anticipation that the two grades would be complementary to each other. It therefore seems necessary that the relative weight of the yield vs quality grade or the rigidity of carcass weight limits of the higher grades be diminished significantly for the final grade to reflect the true carcass value.

\section{Primal yields}

The lean weight increased at a rate of $0.437 \mathrm{~kg}$ per $\mathrm{kg}$ SW which was close to $43.34 \%$ of overall mean of the percentage of lean weight per SW (Table 3). The lean percentage was greater in the gilt vs barrow, which is consistent with the published results (Leach et al., 1996; Martin et al., 1980; Piao et al., 2004) as well as with the notion that more fat is trimmed from the carcass of the barrow than from that of the gilt in proportion to the relative fatness of the corresponding carcass. However, the lean percentage did not change with increasing SW. With respect to the relationship of this variable to $\mathrm{SW}$, either no correlation (Leach et al., 1996) or a negative regression on SW with a low slope (approximately $-0.20 \% / 10-\mathrm{kg}$ SW; Martin et al., 1980) has been reported.

The percent yields of the seven primal cuts were affected by sex and SW to varying extents. The percentages for the shoulder referring to the 'front leg' or picnic, neck

Table 2. Carcass yields and grades and their regressions on slaughter weight (SW)

\begin{tabular}{|c|c|c|c|c|c|c|}
\hline \multirow{2}{*}{ Variable } & \multicolumn{3}{|c|}{ Sex } & \multicolumn{3}{|c|}{ Regression on SW } \\
\hline & Gilt $^{1)}$ & Barrow ${ }^{1)}$ & $P$-value & Slope & SE & $P$-value \\
\hline Carcass $\mathrm{wt}^{2,3)}(\mathrm{kg})$ & $91.4 \pm 0.4$ & $90.8 \pm 0.3$ & 0.187 & 0.783 & 0.018 & $<0.001$ \\
\hline Dressing $^{2,3)}(\%)$ & $75.0 \pm 0.2$ & $74.5 \pm 0.2$ & 0.204 & 0.031 & 0.014 & 0.035 \\
\hline Carcass yield grade ${ }^{2,3,4)}$ & $2.46 \pm 0.06$ & $2.91 \pm 0.06$ & $<0.001$ & -0.064 & 0.003 & $<0.001$ \\
\hline Carcass quality grade ${ }^{5)}$ & $2.64 \pm 0.08$ & $2.70 \pm 0.08$ & 0.654 & -0.008 & 0.005 & 0.131 \\
\hline
\end{tabular}

${ }^{1)} \mathrm{LS}$ means \pm SE. Data were obtained from a total of 96 gilts and barrows.

${ }^{2)}$ Individual animal was the experimental unit.

${ }^{3)}$ Data were obtained from a total of 582 gilts and barrows.

${ }^{4)}$ Grades A, B, C, and D were assigned 4, 3, 2, and 1 points of an arbitrary grade unit, respectively.

${ }^{5)}$ Grades $1^{+}, 1,2$, and 3 were assigned 4, 3, 2, and 1 points of an arbitrary grade unit, respectively. 
Table 3. Primal yields and regressions on slaughter weight (SW)

\begin{tabular}{|c|c|c|c|c|c|c|}
\hline \multirow{2}{*}{ Variable } & \multicolumn{3}{|c|}{ Sex } & \multicolumn{3}{|c|}{ Regression on SW } \\
\hline & Gilt $^{1)}$ & Barrow $^{2)}$ & $P$-value & Slope & SE & $P$-value \\
\hline Lean wt (kg) & $53.0 \pm 0.3$ & $52.1 \pm 0.3$ & 0.040 & 0.437 & 0.018 & $<0.001$ \\
\hline Lean percentage & $43.7 \pm 0.3$ & $43.0 \pm 0.3$ & 0.041 & 0.005 & 0.014 & 0.745 \\
\hline \multicolumn{7}{|l|}{ Primal yield (\%) } \\
\hline Shoulder & $16.7 \pm 0.1$ & $16.8 \pm 0.1$ & 0.408 & -0.014 & 0.005 & 0.008 \\
\hline Neck & $8.64 \pm 0.07$ & $8.74 \pm 0.07$ & 0.359 & 0.009 & 0.004 & 0.030 \\
\hline Loin & $13.3 \pm 0.1$ & $12.6 \pm 0.1$ & $<0.001$ & -0.017 & 0.007 & 0.011 \\
\hline Tenderloin & $1.87 \pm 0.02$ & $1.76 \pm 0.02$ & 0.001 & -0.005 & 0.001 & $<0.001$ \\
\hline Rib & $7.84 \pm 0.07$ & $7.96 \pm 0.07$ & 0.237 & 0.003 & 0.004 & 0.499 \\
\hline Belly & $20.2 \pm 0.2$ & $21.2 \pm 0.2$ & $<0.001$ & 0.037 & 0.009 & $<0.001$ \\
\hline Ham & $31.4 \pm 0.2$ & $30.9 \pm 0.2$ & 0.036 & -0.014 & 0.010 & 0.160 \\
\hline
\end{tabular}

${ }^{1,2)} \mathrm{LS}$ means \pm SE of 91 and 90 animals, respectively.

corresponding to the front loin or Boston butt, loin, and tenderloin regressed on SW with low slopes. In addition, percentages of loin and tenderloin were greater in gilts than in barrows $(p<0.05)$. The percent yield of ham was also greater in the gilt vs barrow $(p<0.05)$, but it had no relation to SW. In this regard, Martin et al. (1980) and Latorre et al. (2004) have reported a slightly negative effect for SW (regression slope $=-0.20 \% / 10-\mathrm{kg} \mathrm{SW}$ in the former study), whereas others (Cisneros et al., 1996; Neely et al., 1979) have reported no effect. However, the effects of sex and SW on the primal yields described above were more of a statistical significance than an economic importance because the magnitudes of the SWrelated changes were not large enough to affect the overall carcass value.

The most noteworthy results of all the effects of sex and SW on the primal yield were a greater yield percentage of belly in the barrow vs gilt $(p<0.01)$ and a positive regression of this variable on SW $(p<0.01)$. Furthermore, not only a $1 \%$ difference between the two sexes (20.2 vs $21.2 \%$ ) but a $0.37 \%$ increase per $10-\mathrm{kg} \mathrm{SW}$ is considered to be significant in this primal. Martin et al. (1980) also have reported a $0.51 \%$ increase in the percent yield of untrimmed belly per 10-kg SW. Obviously, the increased percent yield of the belly accompanying the increase of SW will be a benefit accruing to the packer and/or producer in Korea because the yield of the belly, the most valuable cut, is a most significant determinant of the carcass value.

\section{Physicochemical characteristics of the longissimus muscle (loin)}

The lightness $\left(\mathrm{L}^{*}\right)$ of the loin was not affected by either sex or SW, whereas the redness $\left(a^{*}\right)$, which was not different between the two sexes, increased with increasing
SW (Table 4). The lightness, in general, is not different between the two sexes in the literature, whilst effects of increasing SW on this are inconsistent within a narrow range (Latorre et al., 2004; Leach et al., 1996; Piao et al., 2004; Unruh et al., 1996). The relative redness for the two sexes in these studies was also inconsistent; the effect of SW was either non-significant (Leach et al., 1996; Unruh et al., 1996) or positive (Latorre et al., 2004; Piao et al., 2004) supposedly resulting from an increase in muscular myoglobin content (Laotorre et al., 2004).

The 24-h pH was not affected by either sex or SW. This variable did not change with increasing $\mathrm{SW}$ in a number of studies (Latorre et al., 2004; Leach et al.; 1996; Unruh et al., 1996), but in the work of Cisneros et al., (1996), it decreased slightly with the increase of SW (0.02 unit per $10 \mathrm{~kg}$ ). This implicates that increasing SW within a practical range is not likely to bring about an increased incidence of PSE (pale, soft, and exudative) which can be caused by low postmortem muscular $\mathrm{pH}$ occasionally resulting from a decreased cooling rate in the large carcass (Cisneros et al., 1996).

The percentage of drip loss was greater in gilts than in barrows $(p<0.05)$, but it did not change with the increase of SW. These results are different from the lack of effect of either sex or SW (Leach et al., 1996) as well as the regression on SW (-0.28\%/10-kg SW; Cisneros et al., 1996) of this variable reported by corresponding workers. However, apart from the reason for this difference between the studies, drip loss percentages in the present study were overally low (mean $=2.4 \%$ ), indicating that the incidence of PSE occurring at $\geq 5 \%$ drip loss (Joo et al., 1999; Warner et al., 1997) is not likely to be influenced by either sex or SW. Cooking loss did not differ between the two sexes. Instead, it regressed on SW with a slope of $-1.67 \% / 10 \mathrm{~kg}$. Published results regarding the effect of 
Table 4. Physicochemical characteristics of the longissimus muscle (loin) and regressions of them on slaughter weight (SW)

\begin{tabular}{|c|c|c|c|c|c|c|}
\hline \multirow{2}{*}{ Variable } & \multicolumn{3}{|c|}{ Sex } & \multicolumn{3}{|c|}{ Regression on SW } \\
\hline & Gilt $^{1)}$ & Barrow $^{2)}$ & $P$-value & Slope & SE & $P$-value \\
\hline CIE L* & $53.0 \pm 0.4$ & $54.1 \pm 0.4$ & 0.073 & -0.010 & 0.024 & 0.671 \\
\hline CIE $a^{*}$ & $7.65 \pm 0.18$ & $8.09 \pm 0.18$ & 0.092 & 0.021 & 0.010 & 0.040 \\
\hline 24-h pH & $5.63 \pm 0.02$ & $5.62 \pm 0.07$ & 0.784 & -0.002 & 0.001 & 0.069 \\
\hline Drip loss $(\%)$ & $2.64 \pm 0.15$ & $2.17 \pm 0.15$ & 0.028 & 0.003 & 0.008 & 0.682 \\
\hline Cooking loss $(\%)$ & $33.7 \pm 0.5$ & $32.9 \pm 0.5$ & 0.218 & -0.167 & 0.027 & $<0.001$ \\
\hline \multicolumn{7}{|c|}{ Chemical Composition (\%) } \\
\hline Moisture & $73.8 \pm 0.1$ & $73.5 \pm 0.1$ & 0.168 & -0.013 & 0.008 & 0.101 \\
\hline Protein & $22.3 \pm 0.1$ & $22.2 \pm 0.1$ & 0.849 & 0.029 & 0.006 & $<0.001$ \\
\hline Fat & $2.43 \pm 0.08$ & $2.69 \pm 0.08$ & 0.019 & 0.003 & 0.005 & 0.534 \\
\hline \multicolumn{7}{|c|}{ Composition of fatty acids } \\
\hline $14: 0$ & $1.20 \pm 0.03$ & $1.25 \pm 0.03$ & 0.265 & 0.002 & 0.002 & 0.203 \\
\hline $16: 0$ & $22.1 \pm 0.2$ & $22.4 \pm 0.2$ & 0.132 & -0.017 & 0.009 & 0.071 \\
\hline 18:0 & $3.20 \pm 0.07$ & $3.30 \pm 0.07$ & 0.322 & 0.006 & 0.004 & 0.190 \\
\hline $16: 1$ & $10.6 \pm 0.2$ & $10.8 \pm 0.2$ & 0.459 & 0.002 & 0.011 & 0.853 \\
\hline $18: 1$ & $40.3 \pm 0.3$ & $40.9 \pm 0.3$ & 0.187 & 0.104 & 0.021 & $<0.001$ \\
\hline $18: 2$ & $16.3 \pm 0.3$ & $15.4 \pm 0.3$ & 0.021 & -0.070 & 0.017 & $<0.001$ \\
\hline $20: 4$ & $5.78 \pm 0.23$ & $5.41 \pm 0.23$ & 0.255 & -0.026 & 0.014 & 0.078 \\
\hline
\end{tabular}

${ }^{1,2)} \mathrm{LS}$ means \pm SE of 91 and 90 animals, respectively.

sex and SW on this variable also are not consistent among researchers (Cinseros et al., 1996; Latorre et al., 2004; Leach et al., 1996; Unruh et al., 1996). As could be inferred from the relatively large variation of the cooking loss as well as drip loss within and between these studies in terms of the magnitude of the measurements, the inconsistently reported effects for sex and SW in these two variables may well have resulted from the inherently large variabilities of the methodologies themselves.

Percentages of moisture, protein, and fat in the loin were not influenced by sex or SW, except for a regression of protein percentage on SW and a greater fat content in the barrow vs gilt $(p<0.05)$. The former exception $(0.29 \%$ $/ 10 \mathrm{~kg}$ ), which was similar to a previously reported increase of protein content in the loin between 110- and 130-kg SW (Piao et al., 2004), is intriguing, but its underlying mechanisms as well as biological significances remain to be known. The latter exception seemingly reflecting the greater fatness in the barrow vs gilt was also observed in the cited study. It needs be pointed out, however, that in general, contents of theses chemical components in the loin are minimally affected by sex or SW (Latorre et al., 2004; Monin et al., 1999; Unruh et al., 1996). Composition of fatty acids of the loin was minimally influenced by sex or SW, although there were a few cases in which the fatty acid percentage responded to the effect of the gender or SW. However, a lot more investigation is thought to be necessary to work out the effect of sex and SW on the fatty acids composition because results on this were not consistent even within our own studies.

\section{Sensory characteristics of the major primal cuts}

Sensory characteristics of fresh belly, ham and loin evaluated by the panelists are shown in Table 5. Fat color score or 'darkness,' aroma strength, and off-flavor of the belly were not affected by sex or SW, whereas muscle color score increased with increasing SW with a low slope. The ratio of fat:lean, which tended to be greater in barrows vs gilts $(p=0.09)$, increased with increasing SW $(p<0.01)$. These results are consistent with the relative fatness of the animals as related to the gender and body weight. However, not only the balance of fat:lean but the acceptability was not affected by sex or SW. Overall, the quality of fresh belly is considered to be equal for the two sexes and also not to change significantly with increasing SW between 110 and $138 \mathrm{~kg}$.

In fresh ham, none of the color, aroma, and off-flavor was influenced by sex or SW. Drip score increased with increasing SW $(p<0.01)$ with a low slope $(0.27 / 10 \mathrm{~kg})$, whereas the sex effect on this was insignificant. Conversely, marbling score was greater in the barrow vs gilt $(p<0.01)$, but it did not change with increasing SW. The acceptability, on the other hand, neither differed between the two sexes nor changed with increasing SW. Taken together, meat quality of fresh ham, like that of the belly, 
Table 5. Sensory characteristics of fresh belly, ham, and loin of finishing gilts and barrows and their regressions on slaughter weight (SW)

\begin{tabular}{|c|c|c|c|c|c|c|c|}
\hline \multirow{2}{*}{ Variable } & \multicolumn{4}{|c|}{ Sex } & \multicolumn{3}{|c|}{ Regression on SW } \\
\hline & Gilt & Barrow & SE & $P$-value & Slope & SE & $P$-value \\
\hline \multicolumn{8}{|l|}{ Belly ${ }^{1)}$} \\
\hline Color(fat $)^{3)}$ & 5.19 & 5.22 & 0.16 & 0.873 & -0.002 & 0.009 & 0.848 \\
\hline Color(muscle $)^{3)}$ & 5.83 & 5.73 & 0.14 & 0.642 & 0.022 & 0.008 & 0.009 \\
\hline Aroma $^{3)}$ & 3.53 & 3.59 & 0.06 & 0.479 & 0.002 & 0.004 & 0.606 \\
\hline Off-flavor ${ }^{4)}$ & 1.80 & 1.39 & 0.31 & 0.361 & -0.030 & 0.018 & 0.104 \\
\hline Fat:lean ratio ${ }^{3), 5)}$ & 5.21 & 5.68 & 0.19 & 0.090 & 0.031 & 0.011 & 0.009 \\
\hline Fat:lean balance ${ }^{3), 6)}$ & 5.29 & 5.04 & 0.12 & 0.141 & -0.010 & 0.007 & 0.172 \\
\hline Acceptability $^{3)}$ & 5.42 & 5.30 & 0.11 & 0.443 & 0.002 & 0.007 & 0.727 \\
\hline \multicolumn{8}{|l|}{$\mathrm{Ham}^{1)}$} \\
\hline Color & 6.08 & 5.60 & 0.24 & 0.170 & 0.011 & 0.014 & 0.442 \\
\hline Aroma & 3.66 & 3.62 & 0.08 & 0.725 & 0.001 & 0.005 & 0.885 \\
\hline Off-flavor & 3.09 & 3.19 & 0.08 & 0.373 & -0.001 & 0.004 & 0.891 \\
\hline Drip $^{4), 7)}$ & 5.57 & 5.54 & 0.14 & 0.894 & 0.027 & 0.008 & 0.003 \\
\hline Marbling 3),8) & 3.60 & 4.33 & 0.17 & 0.005 & 0.009 & 0.010 & 0.382 \\
\hline Acceptability & 5.03 & 5.22 & 0.09 & 0.180 & 0.007 & 0.006 & 0.204 \\
\hline \multicolumn{8}{|l|}{ Loin $^{2)}$} \\
\hline Color & 5.77 & 5.56 & 0.12 & 0.241 & 0.011 & 0.008 & 0.164 \\
\hline Aroma & 2.74 & 2.70 & 0.11 & 0.789 & 0.045 & 0.007 & $<0.001$ \\
\hline Off-flavor & 2.12 & 2.09 & 0.08 & 0.724 & 0.017 & 0.005 & 0.001 \\
\hline Drip & 4.96 & 4.99 & 0.16 & 0.903 & 0.056 & 0.010 & $<0.001$ \\
\hline Marbling & 4.60 & 4.83 & 0.16 & 0.331 & 0.064 & 0.010 & $<0.001$ \\
\hline Acceptability & 5.44 & 5.58 & 0.10 & 0.311 & 0.029 & 0.006 & $<0.001$ \\
\hline
\end{tabular}

${ }^{1,2)}$ LS means obtained from 36 and 48 primal cuts fabricated from as many animals, respectively. Each variable was evaluated by seven to twelve sensory panelists according to a 9-point hedonic scale.

${ }^{3)}$ Greater values indicate "darker," "stronger," "superior," and "greater" in color, aroma, fat:lean balance/acceptability, and fat:lean ratio/ marbling, respectively.

${ }^{4)}$ Greater values indicate "more" meaning "worse" in terms of quality.

${ }^{5)}$ Refers to the ratio of total area of fat layers to that of muscle layers.

${ }^{6}$ Refers to the adequacy of the fat:lean ratio.

${ }^{7)}$ Refers to the exudative moisture on the surface.

${ }^{8)}$ Subjectively evaluated based on the marbling standard for the pig carcass of MAF (2007).

is thought to have little relation to sex or SW. To our knowledge, there are no published data regarding the sensory evaluation for the ham or belly, so the present results cannot be compared with any publication.

Fresh loin also did not exhibit any difference between the two sexes in its scores of color, aroma, off-flavor, drip, marbling, and acceptability. In the effect for SW, however, all the scores except that for color increased with increasing SW. Moreover, the slopes of the regressions for the aroma, drip, and marbling $(0.45,0.56$, and 0.64 per $10-\mathrm{kg} \mathrm{SW}$, respectively) are considered not to be insignificant in the practical sense as well. If the regression of the marbling score on $\mathrm{SW}$ is expressed on a percent basis, it corresponds to a $13.6 \%$ increase or improvement of marbling per 10-kg increase in SW. Leach et al. (1996) also have reported a 9.7\% improvement of the former per 10-kg increase of the latter. Collectively, these results suggest that the quality of fresh loin could be improved to some extent by increasing SW.

In the evaluation for cooked meat, the sensory score did not differ between the two sexes or with increasing SW in color, aroma, off-flavor, juiciness, taste, tenderness, or acceptability in any of the three primal cuts, except for the regressions on SW of the acceptability of ham and the aroma of loin. However, the slopes of these two exceptions ( -0.11 and -0.15 per $10-\mathrm{kg} \mathrm{SW}$, respectively) were so low that the regressions were significant only statistically. These are, as a whole, similar to previously reported results for cooked loin on its juiciness, tenderness, and off-flavor (Cisneros et al., 1996; Kim et al., 2006; Leach et al., 1996; Piao et al., 2004). In sum, all these data indicate that sensory characteristics of cooked pork related to its quality are minimally influenced, if not influenced, by SW. 
Table 6. Sensory characteristics of cooked meat and their regressions on slaughter weight (SW)

\begin{tabular}{|c|c|c|c|c|c|c|c|}
\hline \multirow{2}{*}{ Variable } & \multicolumn{4}{|c|}{ Sex } & \multicolumn{3}{|c|}{ Regression on SW } \\
\hline & Gilt $^{1)}$ & Barrow $^{1)}$ & $\mathrm{SE}$ & $P$-value & Slope & $\mathrm{SE}$ & $P$-value \\
\hline \multicolumn{8}{|l|}{ Belly } \\
\hline Aroma ${ }^{2)}$ & 4.64 & 4.72 & 0.09 & 0.519 & -0.008 & 0.005 & 0.115 \\
\hline Off-flavor ${ }^{3)}$ & 1.69 & 1.66 & 0.07 & 0.765 & -0.006 & 0.004 & 0.137 \\
\hline Juiciness $^{2)}$ & 5.30 & 5.36 & 0.08 & 0.552 & 0.007 & 0.004 & 0.110 \\
\hline Taste $^{2)}$ & 5.60 & 5.49 & 0.10 & 0.441 & -0.000 & 0.006 & 0.974 \\
\hline Acceptability $^{2)}$ & 5.36 & 5.47 & 0.11 & 0.489 & 0.001 & 0.006 & 0.909 \\
\hline \multicolumn{8}{|l|}{ Ham } \\
\hline Color & 4.91 & 5.04 & 0.11 & 0.435 & 0.005 & 0.006 & 0.420 \\
\hline Aroma & 3.95 & 4.10 & 0.11 & 0.327 & 0.001 & 0.006 & 0.829 \\
\hline Off-flavor ${ }^{3)}$ & 2.13 & 2.12 & 0.07 & 0.867 & 0.003 & 0.004 & 0.472 \\
\hline Juiciness & 4.41 & 4.56 & 0.15 & 0.488 & -0.002 & 0.008 & 0.792 \\
\hline Tenderness $^{2)}$ & 4.56 & 4.67 & 0.16 & 0.617 & -0.009 & 0.009 & 0.307 \\
\hline Acceptability & 4.70 & 4.73 & 0.11 & 0.835 & -0.011 & 0.006 & 0.007 \\
\hline \multicolumn{8}{|l|}{ Loin } \\
\hline Color & 5.04 & 4.98 & 0.11 & 0.699 & 0.001 & 0.007 & 0.914 \\
\hline Aroma & 2.63 & 2.75 & 0.07 & 0.217 & -0.015 & 0.004 & 0.001 \\
\hline Off-flavor & 2.12 & 2.04 & 0.05 & 0.253 & 0.002 & 0.003 & 0.519 \\
\hline Juiciness & 4.25 & 4.16 & 0.15 & 0.671 & 0.014 & 0.009 & 0.117 \\
\hline Tenderness & 4.41 & 4.45 & 0.16 & 0.877 & 0.019 & 0.010 & 0.055 \\
\hline Acceptability & 4.99 & 4.96 & 0.11 & 0.834 & 0.002 & 0.007 & 0.726 \\
\hline
\end{tabular}

${ }^{1)}$ LS means obtained from 24 primal cuts fabricated from as many animals.

${ }^{2), 3)}$ Evaluated by seven to twelve sensory panelists according to a 9-point hedonic scale.

${ }^{2)}$ Greater values indicate "darker," "stronger," and "more/superior" in color, aroma, and juiciness/tenderness/taste/acceptability, respectively.

${ }^{3)}$ Greater values indicate "more" meaning "worse" in terms of quality.

\section{Conclusions}

In finishing gilts and barrows of a typical lean genotype, growth efficiency is not affected by slaughter weight (SW) within a range of SW approximately between 110 and $140 \mathrm{~kg}$. The carcass yield grade declines visibly with increasing SW beginning approximately from $125 \mathrm{~kg}$ because of the upper limits of the carcass weight required for higher yield grades of the current grading system, whereas the quality grade is not influenced by SW. The yield percentage of the belly, the most valuable cut, increases substantially with increasing SW, whereas those for other cuts are non-significantly affected by SW. The redness and marbling may or may not increase with increasing SW in fresh loin and ham. However, other physicochemical and sensory characteristics of fresh and cooked loin and ham are barely affected by SW. Similarly, sensory characteristics of fresh and cooked belly related to meat quality are not influenced by SW. Taken together, approximately $125 \mathrm{~kg}$ is the maximal SW for both gilts and barrows under the current carcass grading system in which the upper limits of the carcass weight for yield grades A and B are 94 and $98 \mathrm{~kg}$, respectively. However, if the rigid weight limits of the carcass required for the yield grades A and B were to be removed or broadened to accommodate larger carcasses, the SW for gilts, but not that for barrows for their excessive fat content at above $125-\mathrm{kg} \mathrm{SW}$, could be increased up to $135 \mathrm{~kg}$ or even greater without compromising the carcass quality.

\section{Acknowledgments}

This work was supported by grants from Jinju National University, CJ Corp., and the Ministry of Knowledge Economy/Korea Institute of Industrial Technology and Planning through the Regional Animal Industry Center at Jinju National University.

\section{References}

1. AOAC (1990) Official methods of analysis. $15^{\text {th }} \mathrm{ed}$, Association of Official Analytical Chemists, Washington, DC.

2. CIE (1978) Recommendations on uniform color spacescolor difference equations, psychometric color terms. Sup- 
plement no. 2 to CIE Publication No. 15 (E-1.3.1) 1971/(TC1-3). Commission Internationale de'Eclairage, Paris.

3. Cisneros, F., Ellis, M., McKeith, F. K., McCaw, J., and Fernando, R. L. (1996) Influence of slaughter weight on growth and carcass characteristics, commercial cutting and curing yields, and meat quality of barrows and gilts from two genotypes. J. Anim. Sci. 74, 925-933.

4. Ellis, M., Webb, A. J., Avery, P. J., and Brown, I. (1996) The influence of terminal sire genotype, sex, slaughter weight, feeding regime and slaughter-house on growth performance and carcass and meat quality in pigs and on the organoleptic properties of fresh pork. Anim. Sci. 62, 521-530.

5. Folch, J., Lees, M., and Sloane-Stanley G. H. (1957) A simple method for the isolation and purification of total lipids from animals tissues. J. Biol. Chem. 226, 497-500.

6. Gu, Y., Schinckel, A. P., and Martin, T. G. (1992) Growth, development and carcass composition in five genotypes of swine. J. Anim. Sci. 70, 1719-1729.

7. Honikel, K. O. (1987) How to measure the water-holding capacity of meat? Recommendation of standardized methods. In: Evaluation and control of meat quality in Pigs (Tarrant, P. V., Eikelenboom, G., and G. Monin, G. (eds.) pp. 129142, Martinus Nijhoff, Dordecht, the Netherlands.

8. Joo, S. T., Kauffman, R. G., Kim, B. C., and Park, G. B. (1999) The relationship of sarcoplasmic and myofibrillar protein solubility to colour and water-holding capacity in porcine longissimus muscle. Meat Sci. 52, 291-297.

9. Kanis, E., Nieuwhof G. J., de Greef, K. H., van der Hel, W., Vestergen, M. W. A., Huisman, J., and van der Wal, P. (1990) Effect of recombinant porcine somatotropin on growth and carcass quality in growing pigs: interactions with genotype, gender and slaughter weight. J. Anim. Sci. 68, 1193-1200.

10. Kim, I. S., Jin, S. K., Song, Y. M., Park, K. H., Kang, S. M., Ja, J. H., Kim, J. J., Park, Y. S., and Kim, J. H. (2006) Quality characteristics of pork by sex on crossbred pigs. Kor. J. Intl. Agri. 18, 34-39.

11. Kim, Y. S., Kim, S. W., Weaver, M. A., and Lee, C. Y. (2005) Increasing the pig market weight: world trends, expected consequences and practical considerations. Asian-Aus. J. Anim. Sci. 18, 590-600.

12. Latorre, M. A., Lazaro, R., Valencia, D. G., Medel, P., and Mateos, G. G. (2004) The effects of gender and slaughter weight on the growth performance, carcass traits and meat quality characteristics of heavy pigs. J. Anim. Sci. 82, 526533.

13. Leach, L. M., Ellis, M., Sutton, D. S., McKeith, F. K., and Wilson, E. R. (1996) The growth performance, carcass characteristics, and meat quality of halothane carrier and negative pigs. J. Anim. Sci. 74, 934-943.

14. Lee, C. Y., Kim, M., Ha, D. M., Park, J. W., Oh, G. Y., Lee, J. R., Ha, Y. J., and Park, B. C. (2007) Effects of the energy level of the finisher diet on growth efficiency and carcass traits of 'high'-market weight pigs. J. Anim. Sci. Technol. (Kor.) 49, 471-480.

15. Lee, C. Y., Kwon, O. C., Ha, D. M., Shin, H. W., Lee, J. R., Ha, Y. J., Lee, J. H., Ha, S. H., Kim, W. K., Kim, K. W., and
Kim, D. H. (2006) Growth efficiency, carcass quality characteristics and profitability of of finishing pigs slaughtered at 130 vs. 110 kg. J. Anim. Sci. Technol. (Kor.). 48, 493-502.

16. Lee, C. Y., Lee, H. P., Jeong, J. H., Baik, K. H., Jin, S. K., Lee, J. H., and Sohn, S. H. (2002) Effects of restricted feeding, low-energy diet, and implantation of trenbolone acetate plus estradiol on growth, carcass traits, and circulating concentrations of insulin-like growth factor (IGF)-I and IGFbinding protein-3 in finishing barrows. J. Anim. Sci. 80, 8493.

17. MAF. (2005) "Definitions of the primal cuts of animal carcasses" Notification No. 2005-50 of the Ministry of Agriculture and Forestry, Republic of Korea.

18. MAF. (2007) "Grading Standards for Livestock Products" Notification No. 2007-40 of the Ministry of Agriculture and Forestry, Republic of Korea.

19. Martin, A. H., Sather, A. P., Fredeen, H. T., and Jolly, R. W. (1980) Alternative market weights for swine. II. Carcass composition and meat quality. J. Anim. Sci. 50, 699-705.

20. Monin, G., Larzul, C., Le Roy, P. Culioli, J. Rousset-Akrim S. Talmant, A., Touraille, C., and Sellier, P. (1999) Effects of the halothane genotype and slaughter weight on texture of pork. J. Anim. Sci. 77, 408-415.

21. Moon, S. S., Yang, H. S., Park, G. B., and Joo, S. T., (2006) The relationship of physiological maturity and marbling judged according to Korean grading system of meat quality traits of Hanwoo beef females. Meat Sci. 74, 516-521.

22. NASS (2008) Hogs: Commercial Slaughter Average Liveweight by Month and Year, US. National Agricultural Statistics Service. http://www.nass.usda.gov/Charts_and_Maps

23. Neely, J. D., Johnson, R. K., and Walters, L. E. (1979) Efficiency of gains and carcass characteristics of swine of two degrees of fatness slaughtered at three weights. J. Anim. Sci. 48, 1049-1056.

24. NRC (1998) Nutrient Requirements of Swine. 10th ed. National Academy Press, Washington, DC.

25. Park, M. J., Ha, D. M., Shin, H. W., Lee, S. H., Kim, W. K., Ha, S. H., Yang, H. S., Jeong, J. Y., Joo, S. T., and Lee, C. Y. (2007) Growth efficiency, carcass quality characteristics and profitability of 'high'-market weight pigs. J. Anim. Sci. Technol. (Kor.). 49, 459-470.

26. Park, M. J., Jeong, J. Y., Ha, D. M., Park, J. W., Sim, T. G., Yang, H. S., Lee, C. Y., Joo, S. T., and Park, B. C. (2009a) Relationships of the slaughter weight to growth performance and meat quality traits in finishing pigs fed a low-energy diet. J. Anim. Sci. Technol. (Kor.). 49, 135-142.

27. Park, M. J., Jeong, J. Y., Ha, D. M., Park, J. W., Sim, T. G., Yang, H. S., Lee, C. Y., Joo, S. T., and Park, B. C. (2009b) Relationships of the slaughter weight to growth performance and meat quality traits in finishing pigs fed a low-energy diet. J. Anim. Sci. Technol. (Kor.). 51, 135-142.

28. Piao, J. R., Tian, J. Z., Kim, B. G., Choi, Y. I., Kim, Y. Y., and Han, I. K. (2004) Effects of sex and market weight on performance, carcass characteristics and pork quality of market hogs. Asian-Aus. J. Anim. Sci. 17, 1452-1458.

29. Quijandria, B., Jr. and Robinson, O. W. (1971) Body weight 
and backfat deposition in swine: curves and correction factors. J. Anim. Sci. 33, 911-918.

30. SAS. (1996) SAS/STAT Software for PC. Release 6.11, SAS Institute Inc., Cary, NC, USA.

31. Unruh, J. A., Friesen, K. G., Stuewe, S. R., Dunn, B. L., Nelssen, J. L., Goodband, R. D., and Tokach, M. D. (1996) The influence of genotype, sex and dietary lysine on pork subprimal cut yields and carcass quality of pigs fed to either 104 or 127 kilograms. J. Anim. Sci. 74, 1274-1283.

32. Yang, H. S., Moon, S. S., Jeong, J. Y., Choi, S. G., Joo, S. T., and Park, G. B. (2006) Effect of sodium bicarbonate injection in pre-rigor porcine M. Longissimus lumborum on pork quality. Asian-Aus. J. Anim. Sci. 19, 898-904.

33. Warner, R. D., Kauffman, R. G., and Greaser, M. L., (1997) Muscle protein changes post mortem in relation to pork quality traits. Meat Sci. 45, 339-352.

34. Zanardi E., Novelli, E., Ghiretti, G. P., and Chizzolini R. (2000) Oxidative stability of lipids and cholesterol in salame Milano, coppa and Parma ham: dietary supplementation with vitamin E and oleic acid. Meat Sci. 55, 169-175.

(Received 2009.11.4/Revised 2010.2.22/Accepted 2010.3.31) 